\title{
Erratum to: Smoking, Porphyromonas gingivalis and the immune response to citrullinated autoantigens before the clinical onset of rheumatoid arthritis in a Southern European nested case-control study
}

Benjamin A. Fisher ${ }^{1 *+}$, Alison J. Cartwright ${ }^{2^{*+}}$, Anne-Marie Quirke ${ }^{2}$, Paola de Pablo ${ }^{1}$, Dora Romaguera ${ }^{3,4}$, Salvatore Panico ${ }^{5}$, Amalia Mattiello ${ }^{5}$, Diana Gavrila ${ }^{6,7}$, Carmen Navarro ${ }^{6,7}$, Carlotta Sacerdote ${ }^{8}$, Paolo Vineis ${ }^{8}$, Rosario Tumino ${ }^{9}$, David F. Lappin ${ }^{10}$, Danae Apatzidou ${ }^{10}$, Shauna Culshaw ${ }^{10}$, Jan Potempa ${ }^{11,12}$, Dominique S. Michaud ${ }^{3,13}$, Elio Riboli ${ }^{3}$ and Patrick J. Venables ${ }^{2}$

\section{Erratum}

After publication of the original article [1], the publisher was notified that there was a spelling error in one of the author's surnames. Danae Apatzidou's surname was erroneously spelled 'Apazidou'.

\section{Reference}

1. Fisher BA, Cartwright AJ, Quirke A-M, de Pablo P, Romaguera D, Panico S, et al. Smoking, Porphyromonas gingivalis and the immune response to citrullinated autoantigens before the clinical onset of rheumatoid arthritis in a Southern European nested case-control study. BMC Musculoskelet Disord. 2015;16:331.

\begin{abstract}
Author details
'Rheumatology Research Group, Centre for Translational Inflammation Research, Queen Elizabeth Hospital Birmingham, Birmingham B15 2WB, UK. ${ }^{2}$ Kennedy Institute of Rheumatology, University of Oxford, Oxford, UK. ${ }^{3}$ School of Public Health, Imperial College London, London, UK. ${ }^{4}$ CIBER-OBN (Fisiopatología de la Obesidad y Nutrición), Madrid, Spain. ${ }^{5}$ Department of Clinical and Experimental Medicine, Federico II University of Naples, Naples, Italy. ${ }^{6}$ Department of Epidemiology, Murcia Regional Health Council, Murcia Spain. ${ }^{7}$ CIBER Epidemiología y Salud Pública (CIBERESP), Murcia, Spain.

${ }^{8}$ Human Genetics Foundation, Turin, Italy. ${ }^{9}$ Cancer Registry and Histopathology Unit, "Civic - M.P.Arezzo" Hospital, ASP Ragusa, Ragusa, Italy.

${ }^{10}$ University of Glasgow Dental School, University of Glasgow, Glasgow, UK.

${ }^{11}$ Faculty of Biochemistry, Biophysics and Biotechnology, Jagiellonian University, Krakow, Poland. ${ }^{12}$ Oral Health and Systemic Research Group, School of Dentistry, University of Louisville, Louisville, USA. ${ }^{13}$ Department of Epidemiology, Brown University School of Public Health, Providence, USA.
\end{abstract}

Published online: 05 February 2016

* Correspondence: b.fisher@bham.ac.uk; alison.cartwright@kennedy.ox.ac.uk ${ }^{\dagger}$ Equal contributors

${ }^{1}$ Rheumatology Research Group, Centre for Translational Inflammation Research, Queen Elizabeth Hospital Birmingham, Birmingham B15 2WB, UK ${ }^{2}$ Kennedy Institute of Rheumatology, University of Oxford, Oxford, UK

\section{Submit your next manuscript to BioMed Central and take full advantage of:}

- Convenient online submission

- Thorough peer review

- No space constraints or color figure charges

- Immediate publication on acceptance

- Inclusion in PubMed, CAS, Scopus and Google Scholar

- Research which is freely available for redistribution

Submit your manuscript at

www.biomedcentral.com/submit

C BioNed Central 